\title{
Dependence of positive refractivity bias of GPS RO cloudy profiles on cloud fraction along GPS RO limb tracks
}

\author{
S. Yang ${ }^{1} \cdot X . Z^{2}{ }^{2}$
}

Received: 11 August 2015/ Accepted: 20 April 2016/Published online: 3 May 2016

(C) The Author(s) 2016. This article is published with open access at Springerlink.com

\begin{abstract}
We collected global COSMIC RO data from 2009 and 2010 using measurements from the NOAA-18 Advanced Microwave Sounding Unit-A (AMSU-A) along GPS RO limb tracks and also using data from the CloudSat Cloud Profiling Radar (CPR). The collocated AMSU-A liquid water path (LWP) retrieval over the ocean is then used to quantify the dependence of fractional refractivity bias ( $N$-bias) of GPS RO profiles in cloudy conditions on AMSU-A data points with nonzero LWP along GPS RO limb tracks. The collocated CPR cloud type dataset is used for selecting GPS RO profiles in cloudy conditions and for grouping GPS RO cloudy profiles into seven different cloud types. It is shown that the positive fractional $N$-bias varies with cloud fraction along the COSMIC GPS RO limb tracks. It reaches a value between 1 and $2 \%$ when cloud fraction is as high as $90-100 \%$ for altocumulus, altostratus, cirrus, cumulus, and deep convection clouds. For nimbostratus and stratocumulus clouds, large biases are found at any value of cloud fraction. The positive fractional $\mathrm{N}$-bias can be more than $2 \%$ even if cloud fraction is less than about $50 \%$ for nimbostratus and stratus clouds.
\end{abstract}

Keywords GPS RO · Cloud type · Data assimilation

X. Zou

xzou1@umd.edu

1 Joint Center for Data Assimilation Research and Applications, Nanjing University of Information Science and Technology, Nanjing, China

2 Earth System Science Interdisciplinary Center (ESSIC), University of Maryland, 5825 University Research Court, College Park, MD 20740-3823, USA

\section{Introduction}

Global measurements of the vertical profiles of the atmospheric refractivity made by the GPS radio occultation (RO) technique are derived from the measurements of carrier phase delay of two known L-band frequencies, L1 at $1.57542 \mathrm{GHz}$ and $\mathrm{L} 2$ at $1.22760 \mathrm{GHz}$, transmitted from the GPS satellites. The phase delay measurements are first converted to the bending angles of radio wave trajectories and then to the vertical profiles of the atmospheric refractivity (Zou et al. 1999). GPS RO measurements are applicable to both weather and climate studies.

The GPS RO data bias is an important quantity that must be properly estimated for GPS RO data assimilation in numerical weather prediction. Any bias must be removed from the data before such data be assimilated into NWP data systems (Tarantola 1987). When compared with the ECMWF (European Centre for Medium-Range Weather Forecasts) analyses, atmospheric refractivity measurements from COSMIC (Constellation Observing System for Meteorology, Ionosphere and Climate) GPS radio occultation (RO) mission were found to be positively biased in cloudy conditions, and those in clear-sky conditions were not biased (Lin et al. 2010; Zou et al. 2012; Yang and Zou 2012). In these early studies, cloudy ROs were identified through their collocation with clouds observed by the Cloud Profiling Radar (CPR) onboard CloudSat. Due to a very narrow swath of CPR measurements, a GPS RO measurement is declared cloudy when its tangent point is collocated with the CPR-detected clouds. However, GPS RO employs a limb-sounding technique. A GPS refractivity measurement represents an integrated effect of the atmosphere along its limb track over a distance of a few hundred kilometers centered at the tangent point on the propagation bending of the two GPS emitted radio signals. 


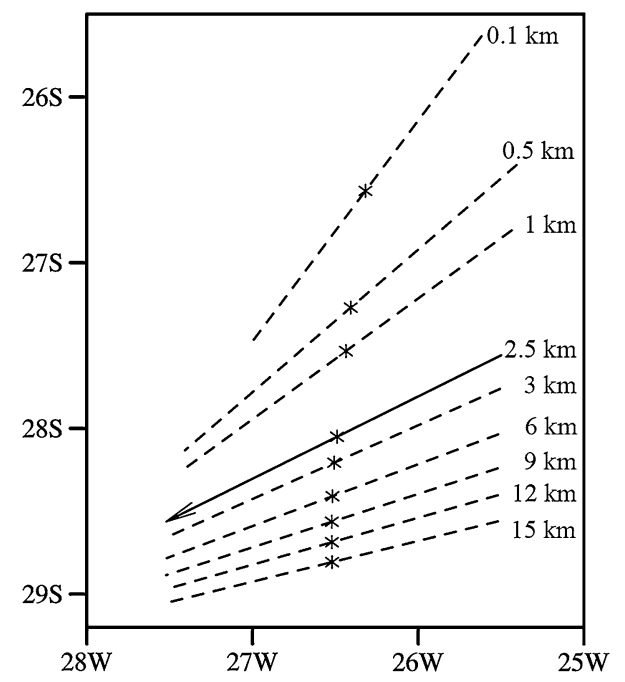

Fig. 1 Tangent lines (solid and dashed line) and tangent points (star symbol) at several specified altitudes of a GPS RO event that occurred at 0042 UTC January 1, 2007, that are mapped into the twodimensional space in latitude and longitude

Figure 1 shows a set of tangent lines and tangent points (star symbol) at several altitudes of a GPS RO event that occurred at 0042 UTC January 1, 2007, that are mapped into the two-dimensional space in latitude and longitude. The mean tangent point position is located at $28.05 \mathrm{~S}$ and $26.49 \mathrm{~W}$, and the tangent line is indicated by a solid line with an arrow indicating the ray path direction. It is seen that both the directions and tangent point positions for the same RO vary with altitude. A more detailed description of the typical geometry of the RO observations can be found in Poli (2004) and Zou (2012). This study extends the work by Yang and Zou (2012) to consider the impacts of cloud fraction along a GPS occulted radio signal propagation track.

COSMIC GPS RO data during 2009 and 2010 are first collocated with CloudSat CPR to identify cloudy ROs as well as cloud types and then collocated with global cloud liquid water path (LWP) data derived from two window channels of the Advanced Microwave Sounding Unit-A (AMSU-A) onboard the polar-orbiting satellite NOAA18. The collocated LWP data along the 600-km GPS limb track of and centered at the average tangent point of each GPS RO profile are used to provide an approximation of cloud fraction information. The dependence of the positive $N$-bias of GPS RO cloudy profiles on cloud fraction along GPS RO limb tracks is quantified for seven different cloud types based on a collocated CPR cloud type dataset. Since the AMSU-A LWP retrievals are available over ocean only, the present study is restricted to ocean clouds only.

\section{Data description}

The following four data types are employed in this study: (i) COSMIC GPS RO refractivity, (ii) CloudSat CPR cloud type, (iii) NOAA-18 AMSU-A LWP, and (iv) ECMWF temperature and humidity. COSMIC GPS RO data have been provided to the international community since April 2006 (Anthes et al. 2008). We use refractivity data of 2009 and 2010 that are data made available by CDAAC (UCAR COSMIC Data Analysis and Archival Center) (Kuo et al. 2004). The daily RO data count is about 2000 during this period. The GPS RO refractivity profile data are provided as a function of altitude at a vertical resolution of approximately $200 \mathrm{~m}$. The horizontal resolution of GPS RO data is approximately $1.5 \mathrm{~km}$ in the cross-track direction and $300 \mathrm{~km}$ in the along-track direction (Kursinski et al. 1996).

The cloudy and clear-sky COSMIC GPS ROs were selected from those COSMIC GPS ROs that were collocated with CloudSat data. CloudSat data have been available since June 2, 2006. The CloudSat satellite orbits the earth approximately every $1.5 \mathrm{~h}$. A 94-GHz and nadir-pointing CPR is the primary observing instrument onboard. It measures the returned backscattered power from clouds as a function of the distance from the CPR. The along-track temporal sample interval equals $0.16 \mathrm{~s}$, the along-track spatial resolution is about $1.1 \mathrm{~km}$, and the effective field of view (FOV) is approximately $1.4 \mathrm{~km} \times 1.7 \mathrm{~km}$ (Tanelli et al. 2008). CloudSat provides a total of 30,000 vertical profiles of radar reflectivity, liquid water content (LWC), ice water content (IWC), a maximum of five cloud layers, cloud type, as well as the altitudes of cloud tops and cloud bases along each of its complete orbits (Stephens et al. 2002).

Further selection is made for NOAA-18 AMSU-Aderived LWP data that are collocated with the limb tracks of all the COSMIC and CloudSat-collocated GPS ROs. Microwave measurements at the two lowest-frequency window channels of AMSU-A are functions of cloud LWP and water vapor path. The LWP and water vapor path can be retrieved using an emission-based radiative transfer model (Greenwald et al. 1993; Weng and Grody 1994; Grody et al. 2001). The cloud LWP used in this study were obtained from measurements at AMSU-A channels 1 and 2 over the ocean using the retrieval algorithm developed by Weng et al. (2003).

The fractional refractivity bias, to be denoted by $\mathrm{N}$-bias for brevity hereafter, is calculated by the following formula:

$\mu_{N}=\overline{\left(\frac{N^{\mathrm{obs}}-N^{\mathrm{ECMWF}}}{N^{\mathrm{obs}}}\right)}$

where $N^{\text {obs }}$ represents GPS RO refractivity observations and $N^{\mathrm{ECMWF}}$ is the model refractivity that is calculated 
from ECMWF analysis of temperature $T^{\mathrm{ECMWF}}$, pressure $P^{\mathrm{ECMWF}}$, and water vapor pressure $P_{\mathrm{w}}^{\mathrm{ECMWF}}$ using the following formula

$N^{\mathrm{ECMWF}}=77.6 \frac{P^{\mathrm{ECMWF}}}{T^{\mathrm{ECMWF}}}+3.73 \times 10^{5} \frac{P_{\mathrm{w}}^{\mathrm{ECMWF}}}{\left(T^{\mathrm{ECMWF}}\right)^{2}}$

where $P^{\mathrm{ECMWF}}$ is in unit $\mathrm{hPa}, T^{\mathrm{ECMWF}}$ is in unit $K$, and $P_{\mathrm{w}}^{\mathrm{ECMWF}}$ is in unit $\mathrm{hPa}$. The first term on the right-hand side of (2) is referred to as the dry term, and the second one is the water vapor term.

The ECMWF analysis of temperature, water vapor, and pressure at model grid points was interpolated to CloudSat data resolution and was included in the CloudSat auxiliary data products. These ECMWF profiles were generated from an ECMWF analysis. It is worth mentioning that COSMIC data above $4 \mathrm{~km}$ are included in ECMWF analyses (Healy and Thépaut 2006).

\section{Collocation among three types of data}

The COSMIC GPS ROs were selected from the subset that was collocated with CloudSat data. The temporal and spatial collocation criteria between GPS RO and CloudSat cloud are $<3 \mathrm{~h}$ and $50 \mathrm{~km}$. The cloud type of each collocated RO profile is determined by the CloudSat profile that is closest to the mean position of the RO profile. There are seven different cloud types: deep convection (Dc), cumulus $(\mathrm{Cu})$, cirrus $(\mathrm{Ci})$, altocumulus (Ac), stratocumulus ( $\mathrm{Sc}$ ), altostratus (As), and nimbostratus (Ns). The cloud type information used in this study is obtained from the 2B-CLDCLASS datasets. The total number of collocated cloudy GPS RO profiles is 6593 .

Once COSMIC GPS ROs collocated with CloudSat CPR data have been selected, further collocation is made between NOAA-18 AMSU-A derived LWP data and the GPS tangent line of $\pm 300 \mathrm{~km}$ length for all the COSMIC and CloudSat-collocated GPS RO profiles. The temporal and spatial collocation criteria are $3 \mathrm{~h}$ and $30 \mathrm{~km}$, respectively, from the $300-\mathrm{km}$-long tangent line that is tangent to the GPS RO limb track at the mean GPS RO tangent point. It is noted that the global cloud LWP data derived from AMSU-A represent the total cloud liquid water amount in a vertical column over a nearly circular area of about $50-100 \mathrm{~km}$ in diameter, but the height of the existing clouds is not known from the satellite imagery. On the other hand, the RO signal is influenced by the medium existing along the ray-tracing path, i.e., line-of-sight medium. Therefore, the collocation conditions between RO data and LWP data are still a crude way for assessing cloud impacts on GPS RO biases.

Figure 2 provides an example of how a real GPS RO profile observed at 1518 UTC August 11, 2009, with its

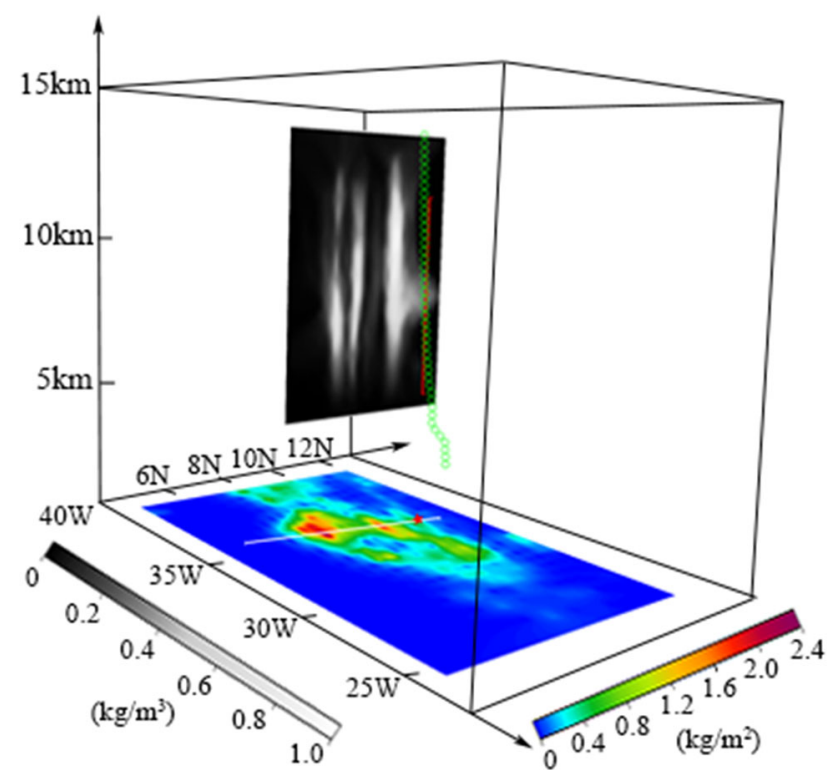

Fig. 2 Example of the collocation of CloudSat CPR, GPS ROs, and cloud liquid water path (LWP) derived from NOAA-18 AMSU-A. A GPS RO profile, the cross section of CPR liquid water content (unit: $\mathrm{kg} / \mathrm{m}^{3}$ ) along a portion of CloudSat track (shaded in black and white) that passed through the observed GPS RO location, and the horizontal distribution of LWP (unit: $\mathrm{kg} / \mathrm{m}^{2}$ ) from NOAA-18 (bottom panel, shaded in color). The red line goes from cloud base to cloud top. The GPS RO location and the CloudSat cross section are indicated in the bottom LWP figure by a red star and a white line, respectively

mean position located at $(12.23 \mathrm{~N}, 32.03 \mathrm{~W})$, is found to be collocated with the CPR measurements along a portion of CloudSat track that passed through the observed GPS RO location, and the horizontal distribution of cloud LWP from NOAA-18 during 1509-1653 UTC on August 11, 2009. The projections of the GPS RO location and the CloudSat cross section are also indicated in the two-dimensional (2D) field of LWP. A slight vertical displacement is seen for the tangent points at different altitudes (green line). The horizontal locations of large LWP, which is a vertically integrated LWC, along the CloudSat track are consistent with the large CPR-measured LWC in the vertical direction.

Figure 3 (top) shows how a set of NOAA-18 AMSU-Aretrieved LWP data points are collocated with each GPS RO tangent line of $600 \mathrm{~km}$ length. The collocated CloudSatdetected cloud location, the GPS RO location at the altitude of the cloud middle, and the amounts of LWP are indicated in Fig. 3. We mention that the AMSU-A field of view, e.g., observation resolution, is slightly more than $50 \mathrm{~km}$ at nadir and increases to more than $100 \mathrm{~km}$ at the largest scan angle of each AMSU-A swath (Zou et al. 2011). It is seen that the total number of LWP data points collocated with a GPS RO tangent line varies from 4 to 10 for the eight examples provided in the top panel. The cloud fraction is defined as 

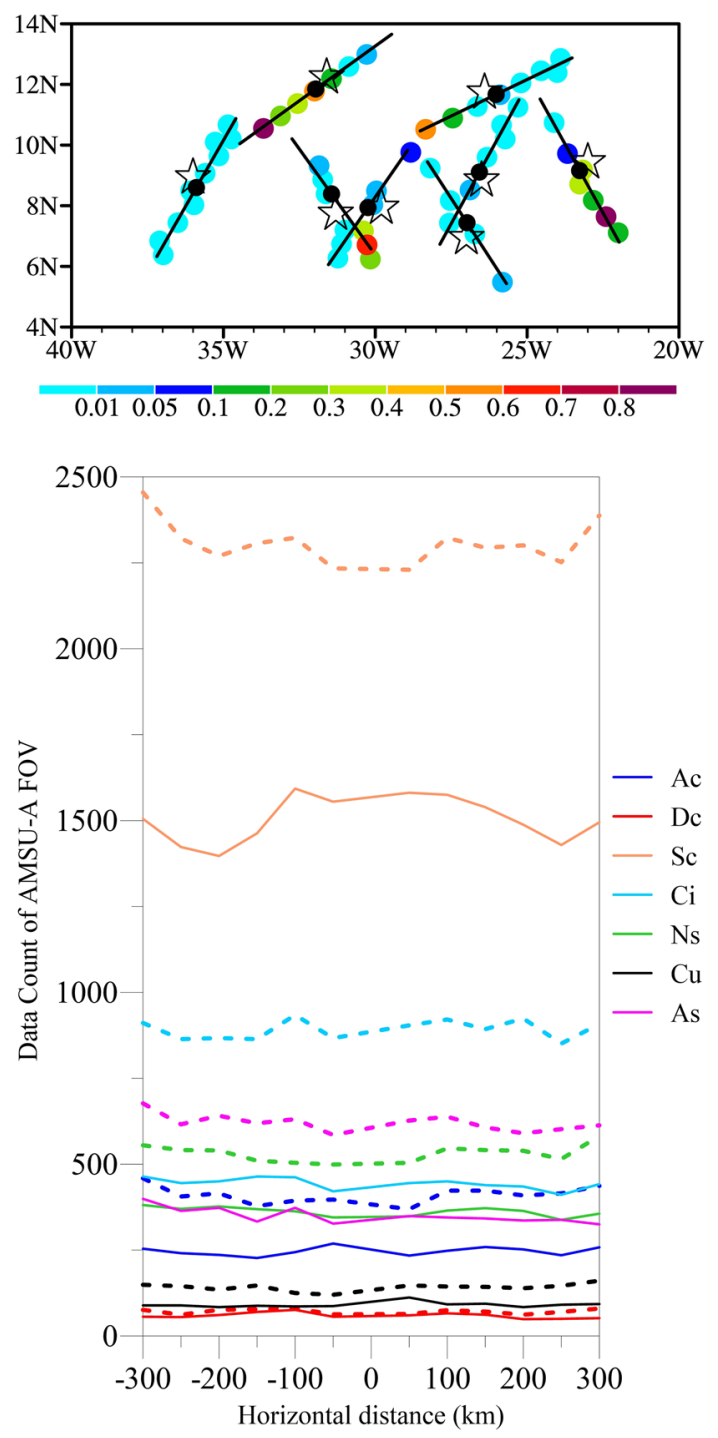

Fig. 3 A three-variable collocation among CloudSat, GPS ROs and AMSU-A, and the total numbers of the collocated AMSU-A FOV. CloudSat-detected cloud location (star), the collocated cloudy GPS RO location at the altitude of the cloud middle (black dot), and NOAA-18 AMSU-A-retrieved LWP (colored dots) along eight GPS RO tangent lines of $600 \mathrm{~km}$ length (black line), as well as the amounts of LWP (unit: $\mathrm{kg} \mathrm{m}^{-2}$ ) indicated in color are shown in top panel. The total numbers of AMSU-A FOV at 50-km interval along the tangent lines (dashed curve) and those with LWP $>0.01 \%$ (solid curve) are given in bottom panel

the ratio of the total number of LWP being $>0.01 \mathrm{~g} \mathrm{~m}^{-2}$ over the total number of collocated LWP data counts. The total numbers of AMSU-A FOV at 50-km interval along the tangent line (dashed) and those with LWP $>0.01 \%$ (solid) are provided in the bottom panel.

The geographical distribution of the cloudy ROs collocated with CloudSat and NOAA-18 AMSU-A-derived LWP in 2009 and 2010 over the ocean is shown in Fig. 4 (top). It is seen that the number of CloudSat-collocated cloudy COSMIC GPS RO profiles is higher in middle and high
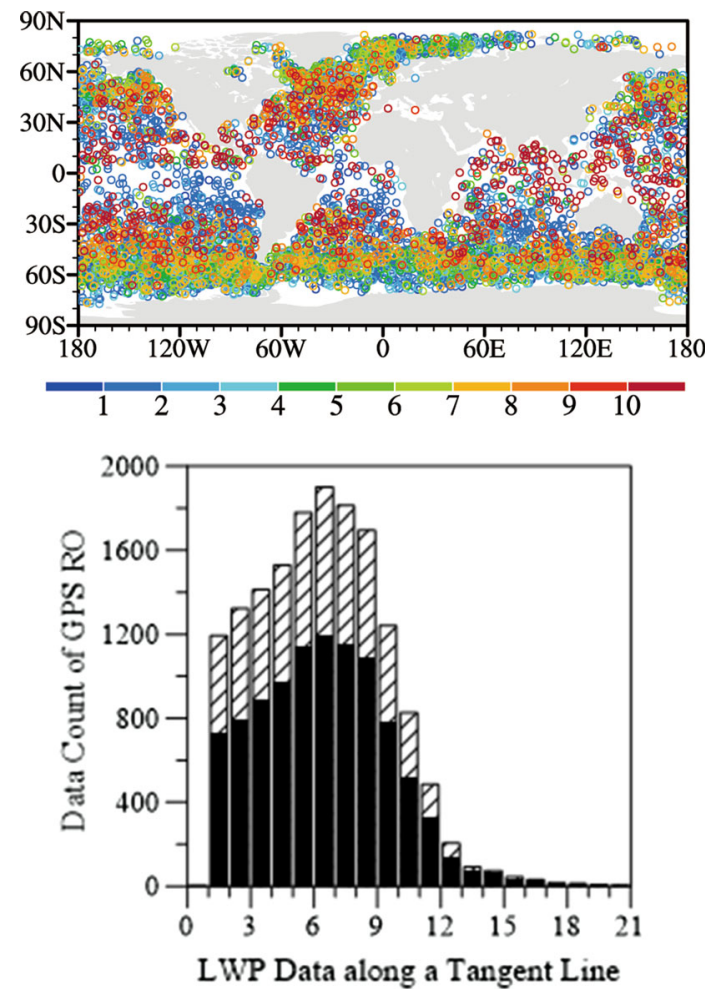

Fig. 4 Global distribution of a total of 6593 GPS RO cloudy profiles that are collocated with CloudSat clouds and NOAA-18 AMSU-A in 2009 and 2010 over ocean. The altitude (unit: $\mathrm{km}$ ) of the cloud middle is indicated in color (top panel). Data counts of COSMIC GPS RO profiles collocated with different numbers of LWP data along each of the GPS RO tangent lines in cloudy (solid) clear-sky (dashed) conditions are seen in the bottom panel

latitudes than in the tropics. This is due to the facts that COSMIC GPS ROs are most populous in middle latitudes and the number of CloudSat profiles increases toward higher latitudes. The altitude of the cloud middle is indicated in the 4 top panel. It is seen that cloud middle altitudes in the tropics and subtropics vary from about $10 \mathrm{~km}$ to about $1-4 \mathrm{~km}$. Clouds in the middle and high latitudes have their cloud middles located between 4 and $7 \mathrm{~km}$.

Figure 4 (bottom) provides the data counts of COSMIC GPS RO profiles collocated with different numbers of LWP data along each of the GPS RO tangent lines in cloudy and clear-sky conditions. For most of GPS RO tangent lines, there are about 6-8 collocated LWP data points. This is expected given the above-mentioned AMSU-A data resolution and the presence of AMSU-A swath gaps in the tropics.

\section{Dependence of positive $N$-bias on cloud fraction along GPS ray path}

Lin et al. (2010) compared large-scale analysis biases in clear-sky and cloudy conditions and found that the COSMIC GPS RO refractivity observations are systematically 
greater than the refractivity calculated from ECMWF analyses, which is to be referred as a positive $N$-bias in clouds. By using LWC observations made available by CloudSat CPR, Yang and Zou (2012) quantified contributions to atmospheric refractivity from LWC to show that GPS signals could be modulated by cloud and precipitation to a level exceeding the GPS RO observation error. Evaluating the GPS $N$-biases by using a collocated single CloudSat profile to represent a cloud environment along a GPS RO limb track has limitation. The global LWP data from AMSU-A onboard the polar-orbiting satellite NOAA18, which has a much wider swath than that of CPR onboard CloudSat, provide an approximation of cloud fraction information so that the dependence of positive $N$ bias of GPS RO cloudy profiles on cloud fraction along GPS RO limb tracks can be assessed. The evaluation of the dependence of positive $N$-bias of GPS RO cloudy profiles on cloud fraction along GPS RO limb tracks will be conducted by grouping all the collocated cloudy ROs into seven different cloud types that are determined at the average tangent point of each RO. Although a single CloudSat profile is likely not representative of cloud type over the entire GPS RO ray path that may contain segments of other clouds and clear-sky, the effects of the same type of clouds for collocated cloudy ROs are likely to be larger than other cloud types. Also, most contributions to GPS RO come from the atmosphere near the tangent point. Results are provided below.

Different clouds are located in different altitudes. The mean and standard deviations of the cloud middle and cloud base altitudes for seven different cloud types as well as all cloud types are shown in Fig. 5. A large variability of both cloud middle and cloud base is found for altocumulus (Ac), altostratus, and cirrus clouds. The variability of both the cloud middle and cloud base is the smallest for stratocumulus (Sc) cloud. The variability of cloud base is much smaller than the variability of cloud middle for cumulus $(\mathrm{Cu})$, deep convection (Dc), and nimbostratus (Ns) clouds. It is thus determined to align all clouds to their cloud bases for a quantification of the fractional $N$-bias within clouds.

The mean fractional $N$ differences within all collocated clouds and seven different cloud types as functions of cloud fraction along the GPS ray path are shown in Fig. 6 by aligning all clouds to their cloud bases. The $N$-biases shown in the figure are calculated with cloud fraction $>0 \%$ (blue), $25 \%$ (green), $50 \%$ (red), and $75 \%$ (black), respectively, at an interval of $0.1 \mathrm{~km}$ in height. It is seen that the fractional $N$-bias is always positive for cloudy GPS ROs. However, the magnitude of the positive fractional $N$ bias varies with cloud fraction and the vertical distance from the cloud base. The $N$-bias is more than $1.6 \%$ within
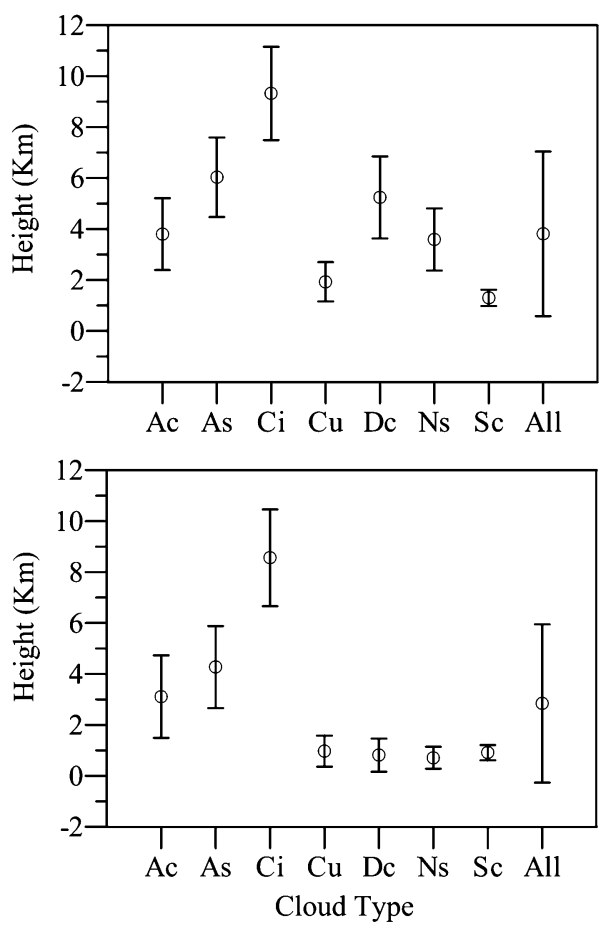

Fig. 5 Mean and standard deviation of the altitudes of cloud middle (top panel) and cloud base (bottom panel) for seven different cloud types as well as all cloud types

altocumulus (Ac) clouds when cloud fraction exceeds $50 \%$ within the cloud layer $0.5-1.0 \mathrm{~km}$ above cloud base. A large positive N-bias of more than $1.6 \%$ is also found with $1.5-2.0 \mathrm{~km}$ layer above altocumulus cloud bases when cloud fraction is more than $75 \%$. For altostratus clouds, the fractional $N$-bias reaches a value of $1.2 \%$ above cloud base when cloud fraction is as high as $75 \%$. The fractional $N$-bias decreases with cloud altitude. The positive $N$-bias is rather small $(\leq 0.2 \%)$ for cirrus clouds. A large variability of the fractional $N$-bias is found in cumulus clouds. The fractional $N$-bias increases with cloud fraction and altitude. The largest positive N-bias is found near the cloud top when cloud fraction is more than $50 \%$ for cumulus cloud. For deep convection (Dc), the fractional $N$-bias is generally small except within the cloud layer $1-2 \mathrm{~km}$ above cloud base and when cloud fraction exceeds $75 \% 3 \mathrm{~km}$ above the cloud base. A thick layer of nimbostratus $(2-4 \mathrm{~km})$ is characterized by a large N-bias exceeding $2 \%$. Contrary to other types of clouds, the fractional $N$-bias is larger when the cloud fraction is smaller at the top of stratocumulus cloud.

The accuracy of the GPS RO refractivity profiles in the lowermost troposphere is about $1 \%$, which comes mainly from the Abel inversion which derives GPS refractivity from the excess phase delay of the GPS radio signals (Kursinski et al. 1995; Kursinski and Hajj 2001), The 
Fig. 6 Variations of the mean fractional $N$ differences and standard deviation for all cloud types and seven single cloud types aligned at the cloud base with respect to cloud fraction along the GPS RO ray path with cloud fraction $>0 \%$ (blue), $25 \%$ (green), $50 \%$ (red), and $75 \%$ (black), respectively. The interval for the $y$ axis is $0.1 \mathrm{~km}$
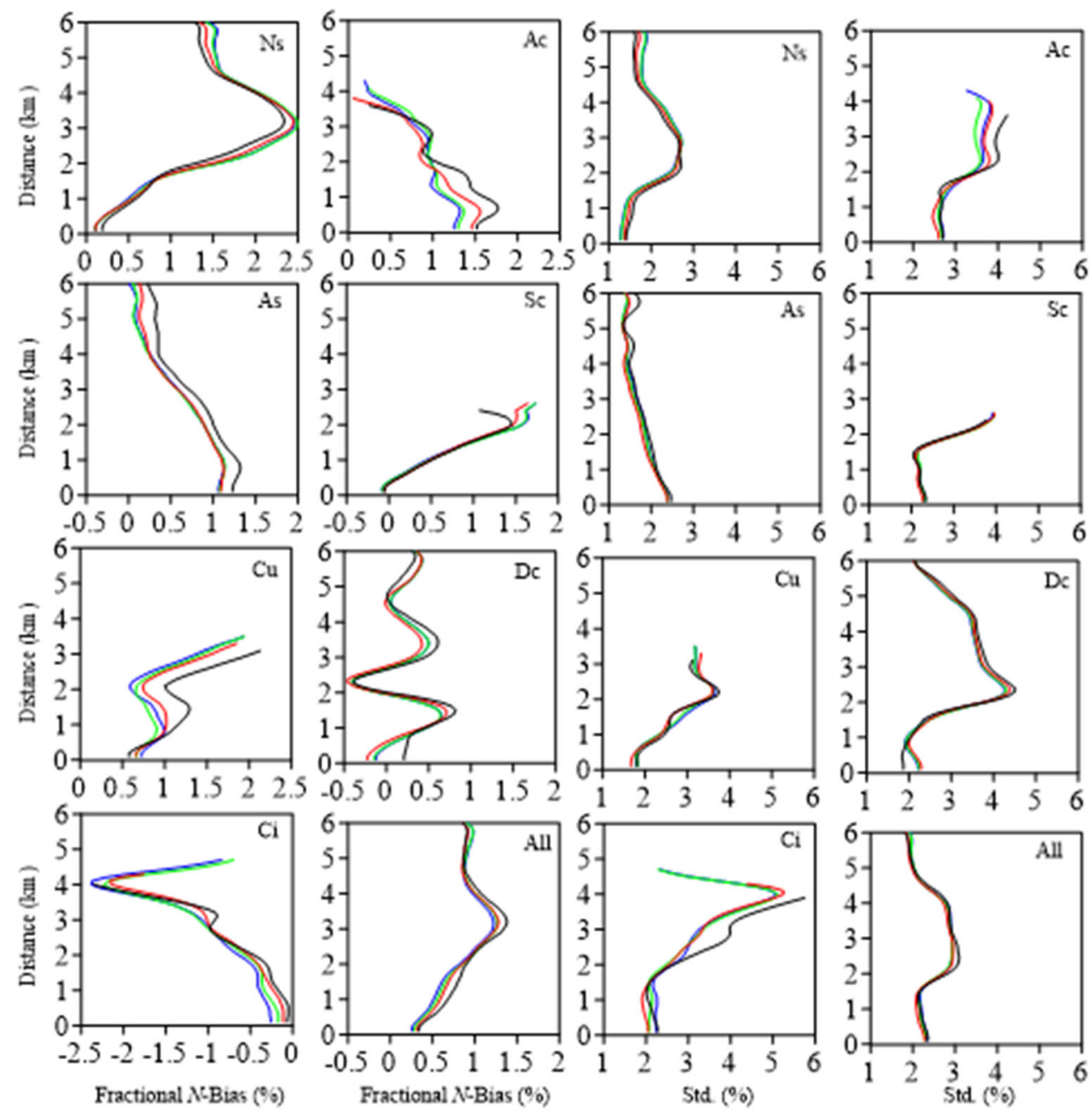

$-0 \sim 100 \%-25 \sim 100 \%-50 \sim 100 \%-75 \sim 100 \%$ horizontal variations of atmospheric refractivity have an effect on GPS RO signals, but cannot be represented in the standard Abel transform (Healy 2001). The 1-2 \% positive $\mathrm{N}$-biases are similar or slightly greater than the accuracy of refractivity estimated in Fig. 6.

The standard deviations of the fractional $N$ differences for seven single cloud types aligned at the cloud base as functions of cloud fraction along the ray path are also provided in Fig. 6. It is pointed out that the number of GPS ROs in cumulus and deep convection clouds is an order of magnitude smaller than those in other cloud types. A large variability of the fractional $N$ differences is found near the cloud top for altocumulus, cirrus, cumulus, deep convection, and stratocumulus clouds. The standard deviations of the fractional $N$ differences are small and do not vary much with respect to cloud fraction and altitude for both altostratus and nimbostratus clouds.

Having shown the accumulative effects of varying cloud fractions on N-bias, which are presented in Fig. 6, we examine the differences of $\mathrm{N}$-bias when cloud fractions are within 0-25, 25-50, 50-75, and 75-100\%. Data counts for seven different cloud types and all clouds as functions of altitude when cloud percentage along the ray path is within 0-25\% (blue), $25-50 \%$ (green), 50-75\% (red), and $75-100 \%$ (black), respectively, are provided in Fig. 7. It is seen that data counts in most clouds are the largest when cloud fraction is more than $75 \%$. An exception is cirrus cloud for which a larger number of cloudy GPS ROs are characterized by a small cloud fraction $(<25 \%)$. The figure also indicates the altitudes of different types of clouds. Most nimbostratus clouds are lower than altocumulus clouds. Altostratus clouds are located around 3-4 km, and stratocumulus clouds are populated at about $1-2 \mathrm{~km}$ altitudes. Cumulus clouds are below $5 \mathrm{~km}$ altitude, and deep convection is found above $4 \mathrm{~km}$ altitude. Cirrus clouds are found above $7 \mathrm{~km}$.

Figure 8 shows the mean fractional $N$ differences as functions of altitude when cloud percentage along the 

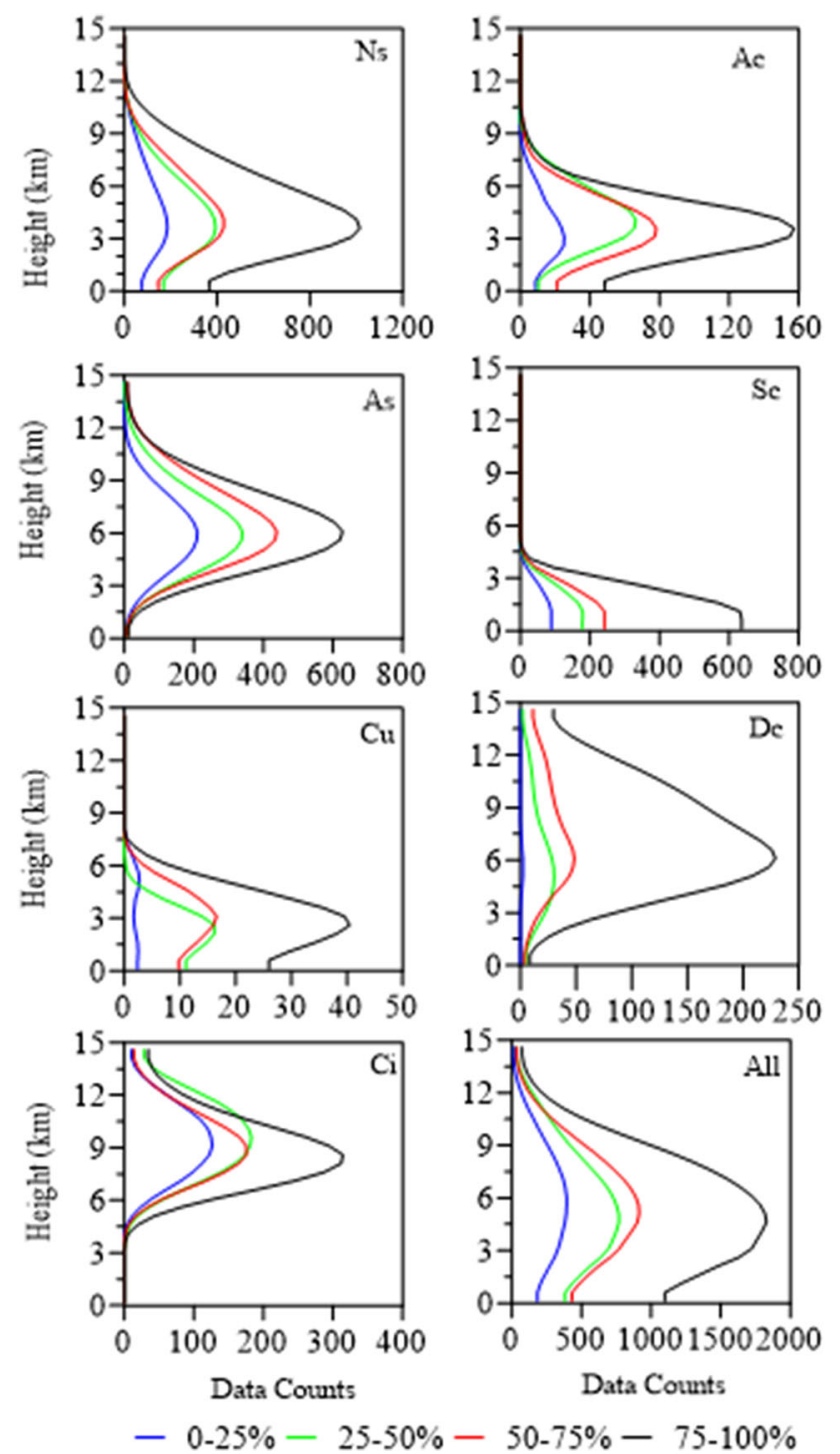

Fig. 7 Data counts for all cloud types and seven single cloud types as functions of altitude when cloud percentage along the ray path is within 0-25\% (blue), 25-50\% (green), 50-75\% (red), and $75-100 \%$ (black), respectively. The interval for the $y$-axis is $0.5 \mathrm{~km}$

ray path is within 0-25\% (blue), 25-50\% (green), 50-75 \% (red), and 75-100\% (black), respectively. The largest $N$-bias is found in the layer between 2.5 and $4.5 \mathrm{~km}$ for all cloud types except cirrus cloud. The fractional $N$-bias is the largest when cloud fraction is more than $80 \%$ for altocumulus and cumulus clouds. For deep convection, the largest fraction $N$-bias is found when cloud fraction is $25-50 \%$. For altostratus, nimbostratus, and stratocumulus clouds, large N-bias can occur at any values of cloud fraction. The standard deviation is in general smaller than $2.7 \%$ except for cirrus cloud top and cumulus clouds where the data counts are the smallest (Fig. 7).
Impacts of cloud absorption on fractional $N$-bias

Impacts of cloud on refractivity are ignored in the refractivity Eq. (2) as well as in the calculation of the fractional $N$-bias using (1). Both Eqs. (1) and (2) are used for the results presented above. Although being of smaller impacts than dry air and water vapor, liquid and ice particles contained in clouds can also affect the propagation of the GPS RO signals through cloud absorption and scattering. Since water droplets and ice particles are much smaller than the GPS RO wavelengths of about $20 \mathrm{~cm}$, the size parameter $\alpha=2 \pi r / \lambda$, where $r$ is the particle radius and $\lambda$ the GPS wavelength, is generally much less than one for cloud particles. The scattering and absorption coefficients can thus be expressed by Rayleigh approximation (Mie 1908). By assuming that the cloud absorption dominates the attenuation of the GPS RO wave propagation, the refractivity due to scattering by water droplets and ice particles is approximately equal to $1.46 W_{\text {water }}$ and $0.69 W_{\text {ice }}$, respectively, where $W_{\text {water }}$ and $W_{\text {ice }}$ are the is liquid water and ice water content in grams per cubic meters (Zou et al. 2012). In other words, the atmospheric refractivity is not only a function of the pressure, temperature, and water vapor pressure as shown in (2), but also a function of liquid water content and ice water content. The mathematical formula of the atmospheric refractivity can be expressed as follows (Kursinski et al. 1997; Zou et al. 2012):

$$
\begin{aligned}
N & =77.6 \frac{P}{T}+3.73 \times 10^{5} \frac{P_{w}}{T^{2}}+1.45 W_{\text {liquid }}+0.69 W_{\text {ice }} \\
& \equiv N_{\text {dry }}+N_{\text {wapor }}+N_{\text {liquid }}+N_{\text {ice }}
\end{aligned}
$$

where $W_{\text {liquid }}$ and $W_{\text {ice }}$ are the LWC and IWC in grams per cubic meters (unit: $\mathrm{g} \mathrm{m}^{-3}$ ). A detailed derivation for the terms $N_{\text {liquid }}$ and $N_{\text {ice }}$ terms in (3), along with a physical understanding of how clouds affect atmospheric refractivity, can be found in Zou et al. (2012).

Ignoring the cloud contributions to the model-simulated atmospheric refractivity, i.e., the third and fourth terms in (3) for the calculation of $N^{\mathrm{ECMWF}}$ in (1), will result in a positive fractional $N$-bias $\mu_{N}$ that is calculated using (1). In order to approximately assess the cloud impacts on the results shown for the positive fractional $\mathrm{N}$-bias, the variations of the CloudSat CPR-measured mean IWC and LWC with altitude are provided in Fig. 9 when cloud percentage along the ray path is within 0-25\% (blue), 25-50\% (green), 50-75\% (red), and 75-100\% (black), respectively, for seven different cloud types and all types of clouds. It is seen that the largest IWC mean $\left(>0.18 \mathrm{~kg} \mathrm{~m}^{-3}\right)$ is found in deep convection in a height range between $6 \mathrm{~km}$ to $12 \mathrm{~km}$ when cloud fraction ranges within 50-75 and 75-100\%. The second largest IWC mean is found within nimbostratus clouds at about $5.5 \mathrm{~km}$. Altostratus and cirrus clouds are mostly occupied by ice at 
Fig. 8 Mean fractional $N$ differences and standard deviation for all cloud types and seven single cloud types as functions of altitude when cloud percentage along the ray path is within 0-25\% (blue), 25-50\% (green), 50-75\% (red), and 75-100 \% (black), respectively. The interval for the $y$-axis is $0.5 \mathrm{~km}$
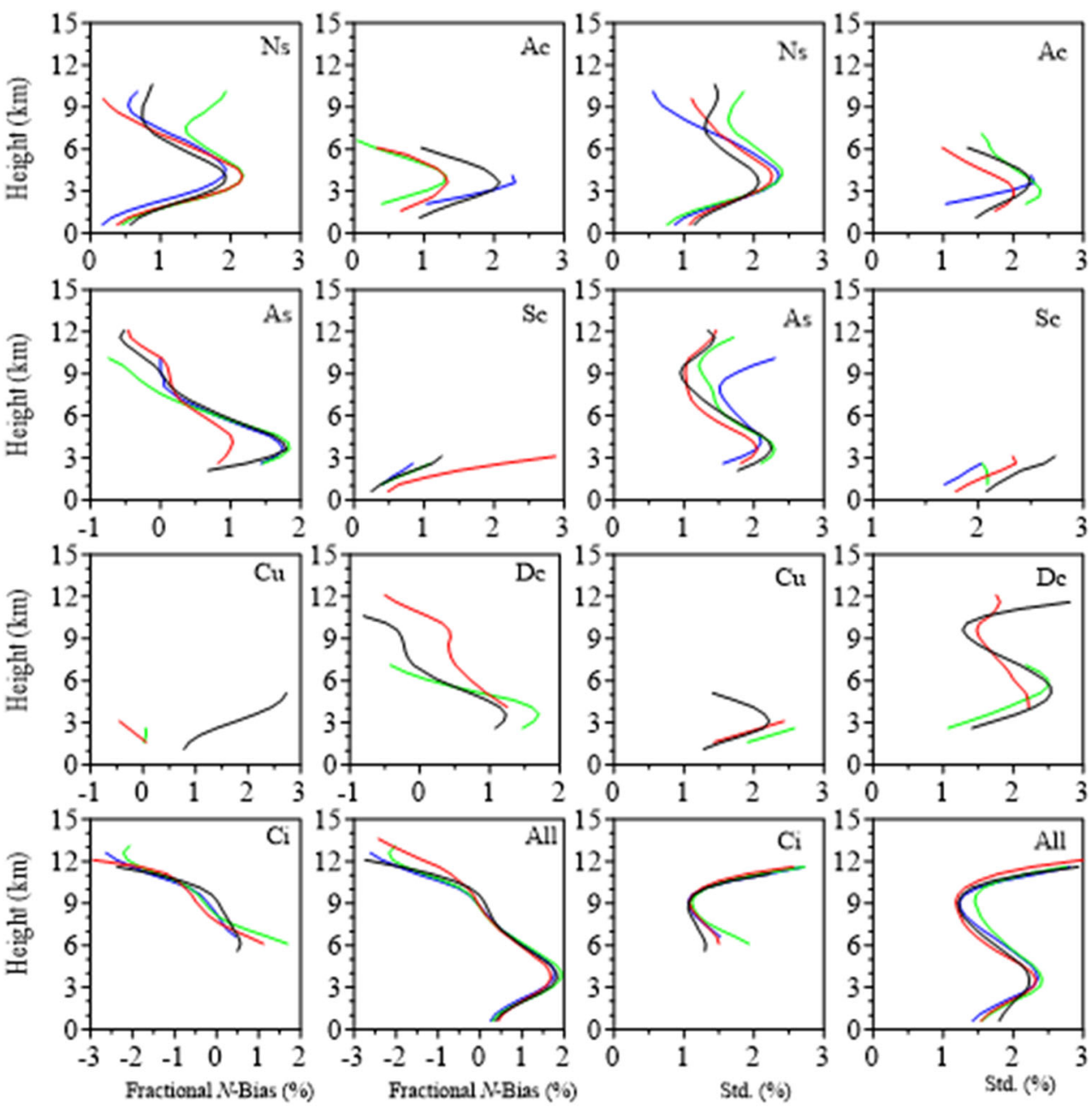

$0-25 \%-25-50 \%-50-75 \%-75-100 \%$ almost all altitudes, with a IWC maximum being located above $10 \mathrm{~km}$ when cloud fractions are within 50-75 and 75-100 \%. Clouds with nonzero LWCs are located below 6-7 km, and large LWC mean values $\left(>0.15 \mathrm{~kg} \mathrm{~m}^{-3}\right)$ are found below $3 \mathrm{~km}$ for all cloud types.

The contribution of cloud to the positive fractional $\mathrm{N}$ bias can be estimated by the following formula:

$\mu_{\text {cloud }}=\overline{\left(\frac{N_{\text {liquid }}+N_{\text {ice }}}{N^{\text {obs }}}\right)}$

Variations of the mean fractional $N$ value associated with clouds, i.e., $\mu_{\text {cloud }}$, with respect to altitude and cloud fraction along the ray path for seven different cloud types and all types of clouds are provided in Fig. 10. A comparison between Figs. 10 and 8 suggests that the impacts of ignoring the cloud absorption contributions to model-simulated atmospheric refractivity is about an order of magnitude smaller than the positive fractional $\mathrm{N}$-bias. As expected, the patterns of the variations of $\mu_{\text {cloud }}$ (Fig. 10) with respect to altitude and cloud fraction are correlated with those of the variations of the mean of IWC and LWC distributions for seven different cloud types and all types of clouds. However, variations of $\mu_{\text {cloud }}$ (Fig. 10) are not correlated with the variations of $\mu_{N}$ (Fig. 8), suggesting that the dominating factors causing the positive $N$-bias in clouds are temperature and water vapor distributions within clouds.

Although the impacts of liquid and ice clouds on the GPS refractivity are more than two orders of magnitude smaller than those of dry and water vapor parts, the positive $N$-bias is robustly known. Given the small percentage of cloud impacts on GPS RO mean fractional differences, it becomes even more important to accurately simulate cloud liquid and ice water mixing ratios for applying GPS RO data for NWP and climate studies. 
Fig. 9 Variations of the mean of IWC and LWC $\left(\mathrm{kg} / \mathrm{m}^{3}\right)$ for seven different cloud types and all types of clouds with respect to cloud fraction along the ray path is within $0-25 \%$ (blue), 25-50 \% (green), 50-75\% (red), and 75-100\% (black), respectively. The interval for the --axis is $0.5 \mathrm{~km}$
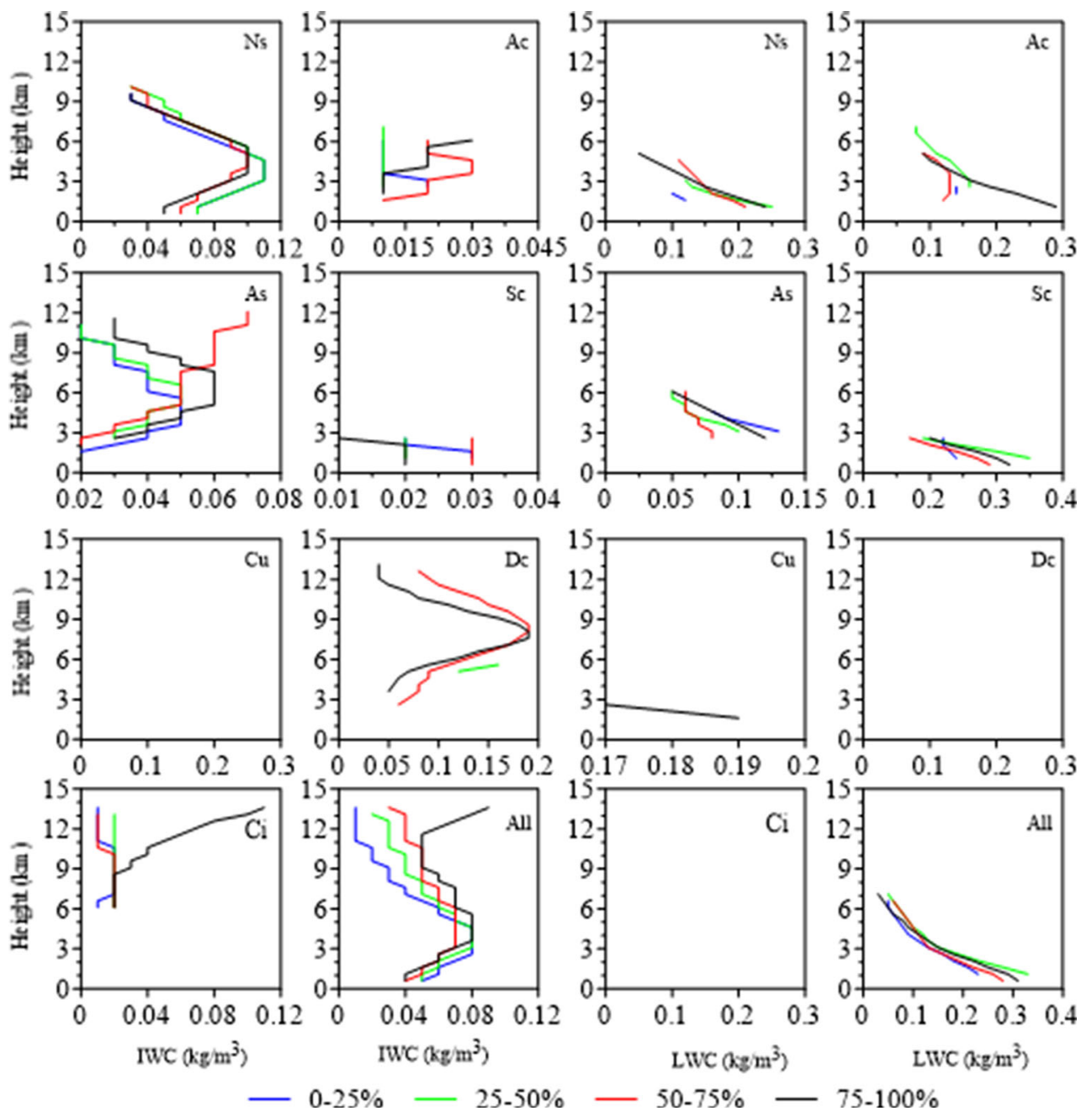

\section{Summary and conclusions}

The positive $N$-biases in clouds are estimated so that they may be removed from GPS RO data assimilation in cloudy conditions. A two-year collocation between GPS ROs, CloudSat, and microwave radiance data from AMSU-A instruments onboard the polar-orbiting meteorological satellite NOAA-18 allowed the impacts of cloud fraction along GPS RO ray paths on $N$-biases be estimated for the first time.

Taking advantages of COSMIC with six LEO satellites to provide GPS ROs, CloudSat with a $94-\mathrm{GHz}$, nadirpointing CPR to provide different cloud types, and LWC and IWC within clouds, and NOAA-18 with a cross-track AMSU-A to provide global LWP over global oceans, two years of collocated cloudy RO profiles were selected to estimate the mean differences between COSMIC GPS RO refractivity retrievals and ECMWF analysis within collocated clouds. Specifically, using CloudSat CPR-measured information on cloud base, cloud top and cloud type and using NOAA-18 LWP-provided cloud fraction information along GPS RO ray paths, a consistent positive $N$-bias could be found within all types of clouds (e.g., deep convection, cumulus, cirrus, altocumulus, stratocumulus, altostratus, nimbostratus) at any cloud fraction. Most cloudy GPS ROs have a high cloud fraction along their ray paths. The mean fractional differences of refractivity between COSMIC GPS ROs and ECMWF analyses vary from 0.2 to $2 \%$ depending on cloud fractions and cloud types. The largest positive $N$-bias is found within nimbostratus clouds for all cloud fractions $(0-100 \%)$ between 2 and $4 \mathrm{~km}$ above cloud bases (or 2.5-4.5 km above the ocean surface).

Future work includes extending the present study to a longer data period from 2011 to 2015 and to also include 

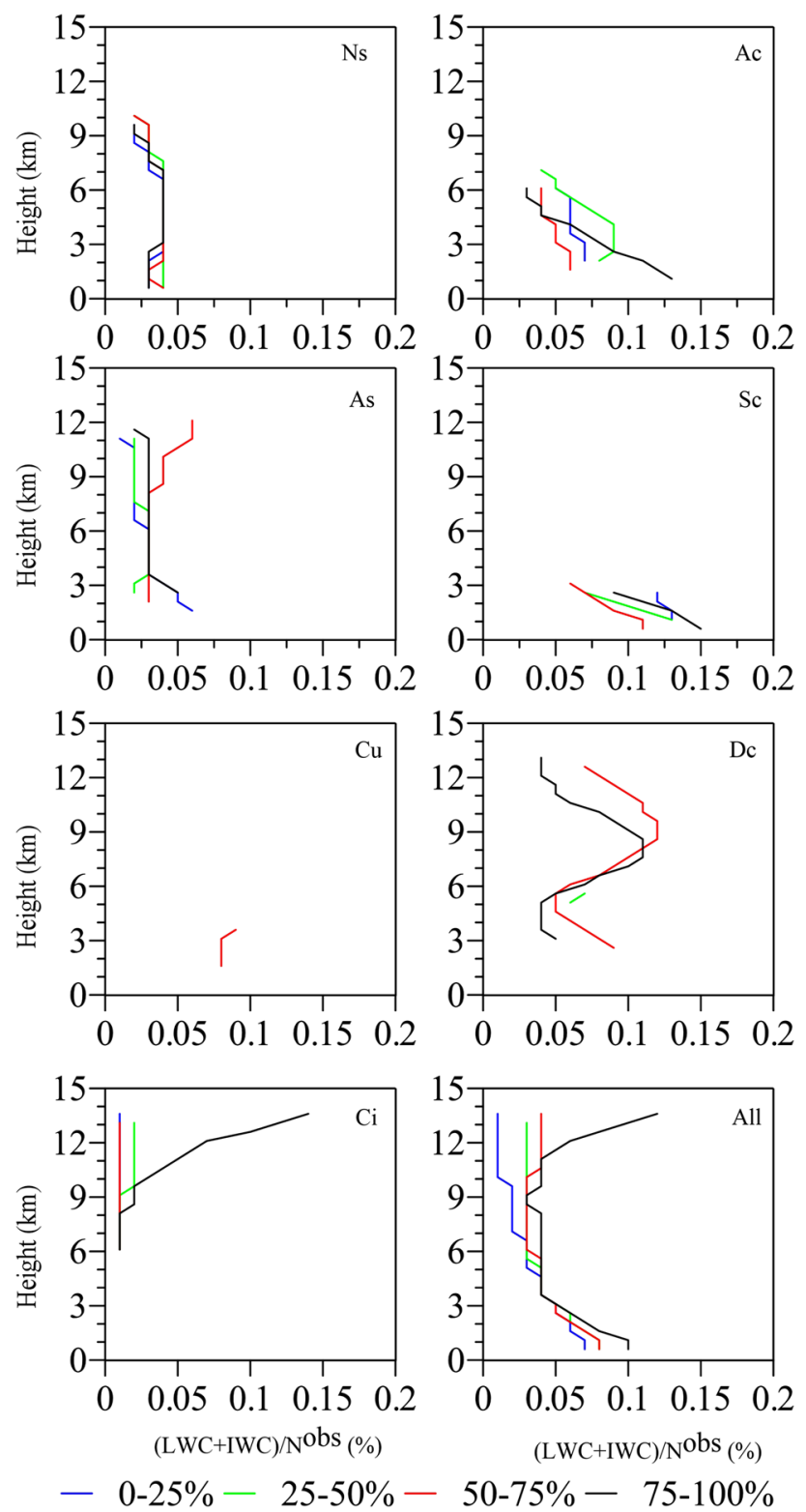

Fig. 10 Variations of the mean of $\mu_{\text {cloud }}(\%)$ for seven different cloud types and all types of clouds with respect to cloud fraction along the ray path is within 0-25\% (blue), 25-50\% (green), 50-75\% (red), and $75-100 \%$ (black), respectively. The interval for the $y$-axis is $0.5 \mathrm{~km}$

collocations with AMSU-A data from other polar-orbiting satellites including NOAA-19, MetOp-A/B, and Advanced Technology Microwave Sounder (ATMS) onboard Suomi NPP.

Acknowledgments This work is jointly supported by National Natural Science Foundation of China (Project No. 41375013), Chinese Ministry of Science and Technology (Project No. 2015CB452805), and China Special fund for Meteorological Research in the Public Interest (Project No. GYHY201406008). The data used for this research can be obtained by emailing to xzou1@umd.edu.
Open Access This article is distributed under the terms of the Creative Commons Attribution 4.0 International License (http://crea tivecommons.org/licenses/by/4.0/), which permits unrestricted use, distribution, and reproduction in any medium, provided you give appropriate credit to the original author(s) and the source, provide a link to the Creative Commons license, and indicate if changes were made.

\section{References}

Anthes R, Berhardt P, Chen Y, Cucurull L, Dymond K, Ector D, Healy S, Ho S, Hunt D, Kuo Y (2008) The COSMIC/Formosat-3 mission. Bull Am Meteorol Soc 89:313-333

Greenwald TJ, Stephens GL, Vonder Haar TH, Jackson DL (1993) A physical retrieval of cloud liquid water over the global oceans using Special Sensor Microwave/Imager (SSM/I) observations. J Geophys Res 98:18471-18488. doi:10.1029/93JD00339

Grody NC, Zhao J, Ferraro R, Weng F, Boers R (2001) Determination of precipitable water and cloud liquid water over oceans from the NOAA-15 advanced microwave sounding unit (AMSU). J Geophys Res 106:2943-2953. doi:10.1029/2000JD900616

Healy S (2001) Radio occultation bending angle and impact parameter errors caused by horizontal refractive index gradients in the troposphere: a simulation study. J Geophys Res 106(D11):11875-11889. doi:10.1029/2001JD900050

Healy S, Thépaut JN (2006) Assimilation experiments with CHAMP GPS radio occultation measurements. Q J R Meteorol Soc 132:605-623. doi:10.1256/qj.04.182

Kuo C, Ade PAR, Bock JJ, Cantalupo C, Daub M, Goldstein J, Holzapfel W, Lange A, Lueker M, Newcomb M (2004) Highresolution observations of the cosmic microwave background power spectrum with ACBAR. Astrophys J 600:32-51

Kursinski E, Hajj G (2001) A comparison of water vapor derived from GPS occultations and global weather analyses. J Geophys Res 106:1113-1138

Kursinski E, Hajj G, Hardy K, Romans L, Schofield J (1995) Observing tropospheric water vapor by radio occultation using the global positioning system. Geophys Res Lett 22:2365-2368

Kursinski E, Hajj G, Bertiger W, Leroy S, Meehan T, Romans L, Schofield J, McCleese D, Melbourne W, Thornton C (1996) Initial results of radio occultation observations of earth's atmosphere using the global positioning system. Science 271:1107-1110

Kursinski E, Hajj G, Schofield J, Linfield R, Hardy K (1997) Observing earth's atmosphere with radio occultation measurements using the global positioning system. J Geophys Res 102:23429-23465

Lin L, Zou X, Anthes R, Kuo Y (2010) COSMIC GPS radio occultation temperature profiles in clouds. Mon Weather Rev 138:1104-1118. doi:10.1175/2009MWR2986.1

Mie G (1908) Considerations on the optics of turbid media, especially colloidal metal sols. Ann Phys 25:377-442

Poli P (2004) Effects of horizontal gradients on GPS radio occultation observation operators. II: a Fast Atmospheric Refractivity Gradient Operator (FARGO). Quart J Roy Meteorol Soc 130:2807-2825. doi:10.1256/qj.03.229

Stephens GL, Vane DG, Boain RJ, Mace GG, Sassen K, Wang Z, Illingworth AJ, O'Connor EJ, Rossow WB, Durden SL (2002) The CloudSat mission and the A-Train. Bull Am Meteorol Soc 83:1771-1790

Tanelli S, Durden SL, Im E, Pak KS, Reinke DG, Partain P, Haynes JM, Marchand RT (2008) CloudSat's cloud profiling radar after two years in orbit: performance, calibration, and processing. IEEE Trans Geosci Remote Sens 46:3560-3573 
Tarantola A (1987) Inverse problem theory: methods for data fitting and model parameter estimation. Elsevier Sci, New York

Weng F, Grody NC (1994) Retrieval of cloud liquid water using the Special Sensor Microwave Imager (SSM/I). J Geophys Res 99:25535-25551. doi:10.1029/94JD02304

Weng F, Zhao L, Ferraro R, Poe G, Li X, Grody N (2003) Advanced microwave sounding unit cloud and precipitation algorithms. Radio Sci. 38(4):8068. doi:10.1029/2002RS002679

Yang S, Zou X (2012) Assessments of cloud liquid water contributions to GPS RO refractivity using measurements from COSMIC and CloudSat. J Geophys Res 117:D06219. doi:10.1029/ 2011JD016452

Zou X (2012) GPS RO data characteristics. Adv Meteorol Sci Technol 2(5):49-54. doi:10.3969/jissn.2095-1973.2012.05.007

Zou X, Vandenberghe F, Wang B, Gorbunov ME, Kuo Y-H, Sokolovskiy S, Chang JC, Sela JG, Anthes R (1999) A raytracing operator and its adjoint for the use of GPS/MET refraction angle measurements. J Geophys Res 104:22301-22318

Zou X, Wang X, Weng F, Li G (2011) Assessments of Chinese FengYun Microwave Temperature Sounder (MWTS) measurements for weather and climate applications. J Ocean Atmos Technol 28:1206-1227

Zou X, Yang S, Ray PS (2012) Impacts of ice clouds on GPS radio occultation measurements. J Atmos Sci 69:3670-3682

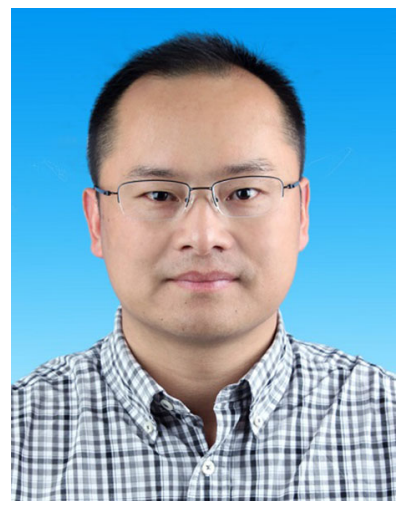

Shengpeng Yang received the Ph.D. degree from Cold and Arid Regions Environmental and Engineering Research Institute, Chinese Academy of Sciences, Lanzhou, China, in 2008. He is currently an Associate Professor with the Joint Center for Data Assimilation Research and Applications, NUIST. His research is focused on GPS RO application on meteorology.
Xiaolei Zou received the Ph.D. degree from the Institute of Atmospheric Physics, Chinese Academy of Sciences, Beijing, China, in 1988. Her research is on satellite data assimilation and their applications to hurricane forecasts and climate-change studies. She was the recipient of the 2008 American Meteorological Society Fellow Award. 